\title{
Development of a Rock Dump Scheduling Model Using Linear Programming
}

\author{
D.J. Williams The University of Queensland, Australia \\ E. Topal The University of Queensland, Australia \\ N. Zhang The University of Queensland, Australia
}

P. Scott HLA ENSR, Australia

\begin{abstract}
This paper describes the preliminary development and application of a rock dump scheduling model, using the operations research technique mixed-integer linear programming implemented in the mathematical modelling language AMPL. The development of the model is initially being focussed on minimising the haulage cost for each open pit block of waste rock to be placed in the rock dump, with some allowance for the selective placement of benign and reactive waste rock, based on an open pit block model that delineates ore, and benign and reactive waste rock. The current formulation is a very simple 3-D model, which will later be implemented using real mine data to fully demonstrate its application. Required input data include xyz-coordinates of the block model for the open pit, identification of whether the waste rock blocks are benign or reactive, the proposed time scheduling of waste rock haulage from the open pit, unit haulage costs, and the geometry of the rock dump and delineation of which zones are to be benign and which reactive. Other parameters to later be added to the model will include the cost of the land covered by the rock dump; the haul road routes between the pit and the dump in xyz-space enabling estimation of haulage distances, grades and actual haulage costs; alternative mining methods; in-pit dumping; topsoil and clay stripping and stockpiling for later rehabilitation purposes; the selective placement of benign and reactive rock to encapsulate the reactive rock; rock dump landform shaping; cover placement; and slope treatment. The model will ultimately provide a tool for rock dump scheduling that meets both the operator's economic and environmental goals.
\end{abstract}

\section{Introduction}

Optimisation techniques, in particular those employing linear programming, have become a common tool in the mining industry for a host of applications, such as open pit production planning, ore blending, ore scheduling, ore haulage, and financial planning. However, the emphasis has been on ore scheduling, with little application to waste rock scheduling.

For surface mining operations, the costs of ore and waste rock excavation and haulage, and waste rock dumping, can be up to $60 \%$ of the total operational cost (Hartman and Mutmansky, 2002), requiring costeffective haulage to maintain the financial viability and maximise the profitability of the operation. In addition, rock dumps may generate acid rock drainage (ARD), with the potential to contaminate surface and ground waters and threaten the ongoing operation and successful rehabilitation of the mine site. Therefore, there is a pressing need to minimise both the high cost of waste rock haulage and the potential for ARD contamination from rock dumps. A well-designed rock dump scheduling tool, based on optimising techniques, would satisfy this need.

This paper addresses the formulation of a model, based on mixed-integer linear programming, to optimise the haulage of waste rock from the open pit to a rock dump at minimum cost and environmental impact. The input data for the model will be based on the given open pit production schedule. 


\section{Background}

\subsection{Mixed-integer linear programming and related surface mine scheduling studies}

Operations research (OR) originated as a field of study in the late 1930s. Mine production planning, in a general sense, is one of the most important areas in which operations research techniques are applied. The OR method most commonly applied to production scheduling problems is known as linear programming (LP). An LP model consists of a linear objective function of the form:

Maximise or minimise:

$$
Z=c_{1} x_{1}+c_{2} x_{21}+c_{3} x_{3}+\ldots+c_{n} x_{n}
$$

subject to a set of linear constraints, without loss of generality, of the following form:

$$
\begin{aligned}
& a_{11} x_{1}+a_{12} x_{2}+a_{13} x_{3} \ldots \ldots \ldots . .+a_{1 n} x_{n} \leq b_{1} \\
& a_{21} x_{1}+a_{22} x_{2}+a_{23} x_{3} \ldots \ldots \ldots . .+a_{2 n} x_{n} \leq b_{2} \\
& \vdots \\
& a_{m 1} x_{1}+a_{m 2} x_{2}+a_{m 3} x_{3} \ldots \ldots \ldots . .+a_{m n} x_{n} \leq b_{m}
\end{aligned}
$$

and a set of non-negativity restrictions:

$$
x_{1}, x_{2} \ldots \ldots x_{n} \geq 0
$$

In this formulation, $Z$ is the value of the objective function, for example, the cost or profit; $x_{i}$ are the decision variables, $a_{i j}$ and $c_{j}$ are constants whose values are dictated by the nature of the problem, and $b_{j}$ is the available amount of the resource $j$.

In certain situations, the decision variables must assume integer values. When this restriction is added to the problem, the model is called an integer programming (IP) model. Such a requirement arises naturally when the variables represent entities that cannot be divided. Integers, specifically binary variables, are used to capture "yes/no" decisions such as whether or not to dump the waste rock in a particular location in the rock dump during a given time period. For example, if block $i$ is dumped in a particular location during a given time period, $x_{i}$ assumes the value of 1 , meaning that this location is no longer available for dumping, and 0 otherwise.

If some variable values are allowed to be continuous, while others must assume integer values, the resulting model is a mixed-integer linear programming (MILP) model. These models are as difficult to solve as IPs (Topal, 2003).

Optimisation methods such as LP and MILP have been applied successfully to surface and underground mine scheduling to improve the net present value of the operation. The first applications of LP to mining were for open cut optimisation (Johnson, 1968). Wilke and Reimer (1977) used LP to develop a short-term schedule for optimising the extraction of ore and waste rock from a given production block in an open pit mine. Dagdelen (1985) formulated an MILP open pit scheduling model. Ramazan (2007) presented a new algorithm to reduce the integer variables for open pit mine scheduling.

In addition to their application to surface mine scheduling, optimisation methods have also been applied to underground mine scheduling over last two decades. Alford (1995) pointed out a number of problems related to underground mine optimisation. Trout (1995) used an MILP model to develop an underground copper mine ore production schedule. Topal (2003) used MILP to optimise production scheduling for the underground sub-level caving operation at Kiruna Mine, Sweden. Nehring and Topal (2007) used MILP to optimise production scheduling for an underground sub-level stoping operation.

\subsection{Haulage costs in surface mining operations}

The modern life-of-mine is often divided into five stages: prospecting, exploration, development, exploitation, and reclamation (Hartman and Mutmansky, 2002). Table 1 represent the main activities, their 
durations, and the 2002 US \$ costs of each of these stages. During the exploitation stage of surface mining, the operational costs typically include:

- Land clearing and topsoil removal.

- Drill and blast.

- Loading.

- Haulage and dumping.

- Pit dewatering and ground support.

- Support services (for example, road construction and maintenance).

- Maintenance services (for example, equipment serving, tyre handling, craneage).

- Rehabilitation.

Table 1 Life-of-mine costs (after Hartman and Mutmansky, 2002)

\begin{tabular}{lllll}
\hline Stage & Purpose & $\begin{array}{l}\text { Duration } \\
\text { (years) }\end{array}$ & $\begin{array}{l}\text { Unit Cost } \\
\text { (US \$/ton) }\end{array}$ & $\begin{array}{l}\text { Total 20-Year Cost } \\
\text { (US \$ million) }\end{array}$ \\
\hline $\begin{array}{llll}\text { Prospecting } \\
\text { Exploration }\end{array}$ & Search for ore & 1 to 3 & 0.05 to 1.00 & 0.2 to 10 \\
Development & Opening ore deposit for production & 2 to 5 & 0.25 to 10.00 & 10 to 500 \\
Exploitation & Production of ore & 10 to 30 & 2.00 to 150 & 100 to 1000 \\
Reclamation & Restoration of site & 1 to 10 & 0.20 to 4.00 & 1 to 20 \\
Total Cost & & & & $\mathbf{1 1 2 . 2}$ to $\mathbf{1 5 4 5}$ \\
\hline
\end{tabular}

The loading, haulage and dumping costs, representing up to $60 \%$ of the total costs of surface mining operations, are the major cost of exploitation, and Table 1 shows that the cost of the exploitation stage accounts for about $89 \%$ to $65 \%$ of the total cost. Loading and haulage of ore and waste rock is conventionally carried out by shovel and truck operations, involving the capital costs of the shovels and haul trucks, fuel costs and haul truck tyre costs. The cost of fuel depends on the purchase cost, and the consumption rate, which can be estimated at $0.31 /$ hour $/ \mathrm{kW}$ of engine capacity. Tyre costs depend on their purchase cost and tyre life (AusIMM, 1993). The haulage cost is mainly determined by haulage hours.

The speed of a haul truck on a 1 in $10 \mathrm{ramp}$ is up to four or five times slower than on the flat, and fuel consumption and tyre wear are greater on ramps, making horizontal haulage about five times more costeffective than haulage up ramps. Therefore, rock dumps of large areal extent and limited height involve lower haulage hours and are more cost-effective to construct than rock dumps of limited aerial extent and significant height. However, rock dumps of large aerial extent represent large catchments for rainfall infiltration, which has the potential to transport large ARD loads to the environment.

\subsection{Causes of and treatment strategies for acid rock drainage}

Acid rock drainage is produced when sulphide-bearing material is exposed to oxygen and water. The mining of sulphidic ore bodies produces sulphidic waste rock, resulting in the potential for ARD generation and release to the environment from the surface rock dumps in which suphidic waste rock is stored. In addition, as the $\mathrm{pH}$ of the pore water within the rock dump drops, metals present can dissolve and are also transported with the ARD, increasing the potential for harm to the receiving environment and any downstream inhabitants (Kleinmann, 1991).

Oxygen will enter a rock dump from the well-oxygenated, coarse-grained, base rubble zone, from where it goes up the coarse-grained angle of repose layers within the dump, and then diffuses into the adjacent fine- 
grained angle of repose layers. Oxygen can also enter the dump via the loose side slopes and can diffuse through the traffic-compacted top surface. Water enters a rock dump through rainfall infiltration, and may capture and transport to the environment any oxidation products it comes into contact with within the dump.

Waste rock can be classified into two basic categories:

- Benign, including weathered (oxidised) rock excavated from above the groundwater table and fresh unmineralised rock excavated from below the ground water table outside the hallo of mineralisation.

- Reactive, fresh mineralised rock, generally excavated from below the groundwater table, likely to contain sulphidic minerals.

For an open pit developed as a single excavation, the majority of the benign waste rock will be excavated at shallow depth in the early stages of the operation, while as the pit deepens the proportion of reactive waste rock will rise, as is illustrated in the simplified open pit cross-section shown in Figure 1. This sequencing of benign and reactive waste rock makes it difficult to encapsulate the reactive waste rock with benign waste rock. For an open pit developed as a series of push-backs, benign and reactive waste rock streams are produced in sequence, making encapsulation of the reactive waste rock with benign waste rock more easily achieved.

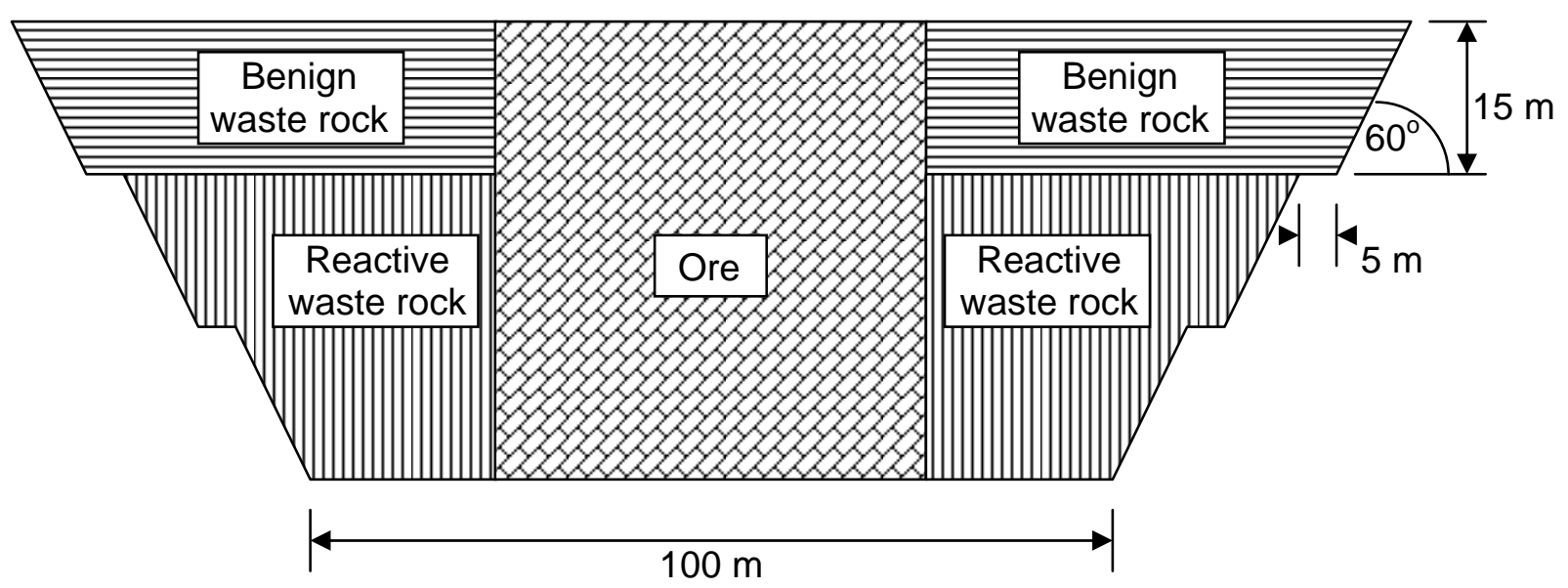

Figure 1 Typical locations of ore, and benign and reactive waste rock in a simplified open pit

The encapsulation of reactive waste rock by benign waste rock is illustrated in Figure 2 (based on Williams et al., 2006). The base layer of benign waste rock provides for the underflow of clean runoff from upslope of the rock dump, the wide side encapsulation with benign waste rock ensures that no reactive waste rock is located beneath the side slopes of the dump through which it is difficult to limit rainfall infiltration, and the post-closure cover of benign material over the top, flat, traffic-compacted surface of the dump is designed to limit the percolation of incident rainfall into the underlying reactive waste rock. A store/release cover has been demonstrated to be effective as a low percolation cover in semi-arid climates, limiting percolation to $<1 \%$ of annual rainfall (Williams et al., 2006).

\section{Model formulation and example application}

\subsection{Model formulation}

The surface rock dump scheduling model is based on MILP optimisation methods, allowing for:

- The integration of waste rock dumping with open pit mining.

- Variable waste rock haulage costs, recognising that haulage up a 1 in 10 ramp costs about five times the cost of horizontal haulage, causing dumps to expand outwards before they go up in a series of lifts. 
- The selective placement of benign and reactive waste rock, allowing the encapsulation of reactive waste rock with benign waste rock, to minimise potential environmental impacts.

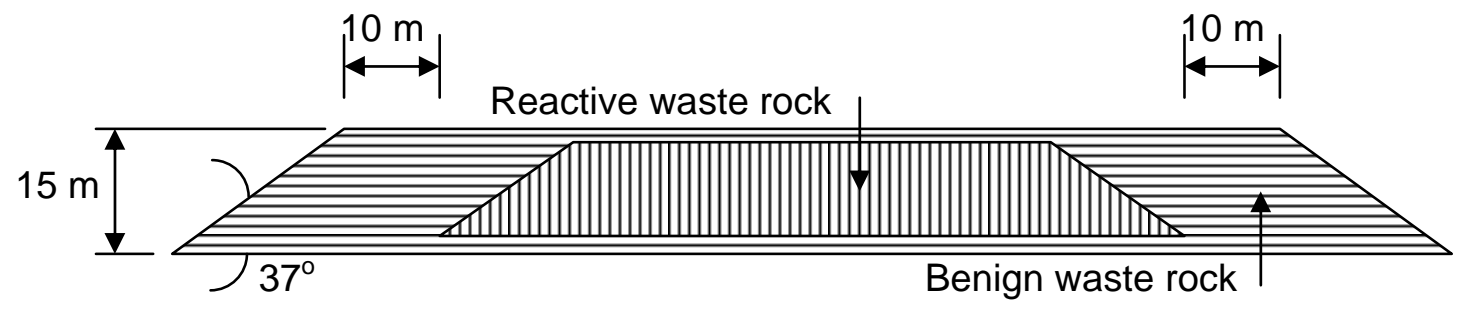

Figure 2 Encapsulation of reactive waste rock by benign waste rock in the dump

\subsubsection{Indices}

Indices are used to describe the locations of blocks in the open pit and the rock dump, and are defined as follows:
ijm $=$ Index of waste rock block ijm in the open pit, where $i$ and $j$ are the locations in plan and $m$ is the vertical location beneath the original surface
$p k n=$ Index of waste rock block $p k n$ in the rock dump, where $p$ and $k$ are the locations in plan and $n$ is the lift number above the original surface.

In addition, the time period $t$, which describes the staging of mining and dumping, has values ranging from 1 (at the commencement of mining and dumping) to $\mathrm{T}$ (at the completion of mining and dumping).

\subsubsection{Sets}

Sets are used to describe groupings, as defined in the following:
$T=\quad$ Duration of mining and dumping.
$O_{t}=$ Set of waste rock blocks to be mined from the open pit during time period $t$.
$B_{t}=$ Set of waste rock blocks to be placed in the rock dump during time period $t$.
$B=$ Set of waste rock blocks in the open pit containing benign material.
$R=$ Set of waste rock blocks in the open pit containing reactive material.
$B^{\prime} \quad=\quad$ Set of waste rock blocks in the rock dump containing benign material.
$R^{\prime} \quad=\quad$ Set of waste rock blocks in the rock dump containing reactive material.

\subsubsection{Parameters}

The model includes a number of parameters, as defined in the following:
$C=$ Unit cost of hauling $1 \mathrm{~m}^{3}$ of waste rock a distance of $1 \mathrm{~km}$ on the flat, in $\$ / \mathrm{m}^{3} / \mathrm{m}$.
$C^{\prime}=$ Unit cost of hauling $1 \mathrm{~m}^{3}$ of waste rock a distance of $1 \mathrm{~km}$ on a 1 in $10 \mathrm{ramp}$, in $\$ / \mathrm{m}^{3} / \mathrm{m}$.
$D_{i j m, p k n} \quad=\quad$ Haul distance on the flat involved in moving the waste rock block from location ijm in the open pit to location pkn in the rock dump, in $\mathrm{m}$.
$D_{i j m, p k n}^{\prime}=$ Haul distance on 1 in 10 ramps involved in moving the waste rock block from location ijm in the open pit to location pkn in the rock dump, in $\mathrm{m}$.
$R_{i j m}=\quad$ Volume of waste rock contained in block ijm in the open pit, in $\mathrm{m}^{3}$. 


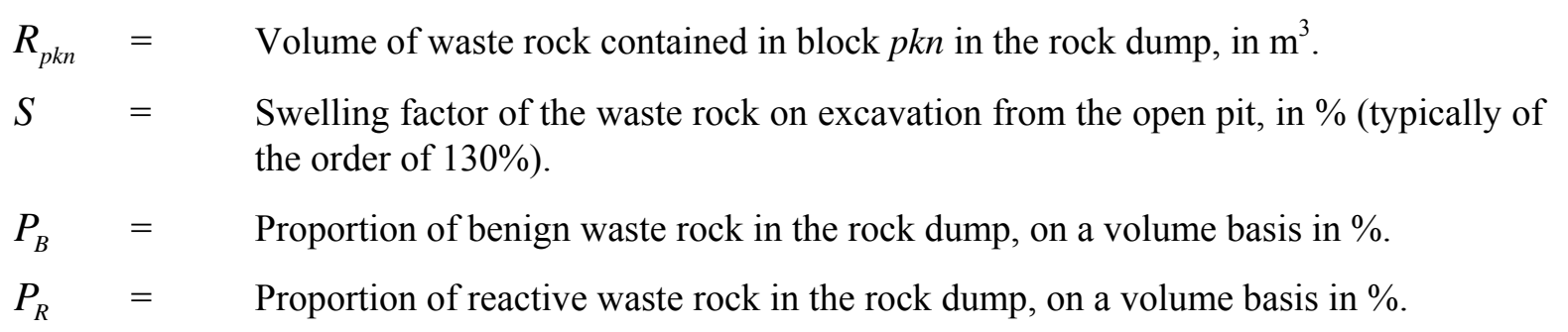

\subsubsection{Variables}

Two types of variables are used in the model; (i) integer or decision variable $W$, and (ii) linear variable $V$, which are defined as follows:

$$
\begin{array}{ll}
W_{p k n}^{t} & =\begin{array}{l}
\text { Decision variable indicating which locations in the rock dump are full at a } \\
\text { given time period } t .
\end{array} \\
= & \begin{array}{l}
1, \text { if full and } 0 \text { if not. } \\
V_{i j m, p k n}^{t}
\end{array} \quad \begin{array}{l}
\text { Volume of waste rock hauled from location ijm in the open pit to location } \\
p k n \text { in the rock dump during time period } t .
\end{array}
\end{array}
$$

\subsubsection{Objective function}

The objective function of the model is to minimise the waste rock haulage cost by optimising the haul distance and height of dumping. The objective function is given by:

$$
\operatorname{Min} \sum_{t \in T} \sum_{i j m \in O_{t}, p k n \in B_{t}}\left(V_{i j, p k n}^{t} C D_{i j m, p k n}+V_{i j m, p k n}^{t} C^{\prime} D^{\prime}{ }_{i j m, p k n}\right)
$$

\subsubsection{Applied model constraints}

Five constraints are applied in the current model, as detailed below.

1. Reserve constraint for the open pit, the purpose of which is to make sure all of the waste rock, both benign and reactive, is hauled to the rock dump:

$$
\sum_{t \in T} \sum_{i j m \in O_{t}, p k n \in B_{t}} V_{i j m, p k n}^{t}=R_{i j m}
$$

2. Capacity constraint for the rock dump, the purpose of which is to prevent the volume of waste rock hauled from the open pit to the rock dump exceeding its storage capacity:

$$
\sum_{t \in T} \sum_{i j m \in O_{t}, p k n \in B_{t}} V_{i j m, p k n}^{t} \leq R_{p k n}
$$

3. Rock dump sequencing constraints, the purpose of which are to ensure that locations in the lower lifts of the dump are filled before locations above them in subsequent lifts are:

$$
\begin{aligned}
& \sum_{t \in T} \sum_{i j m \in O_{t}, p k n \in B_{t}} S V_{i j m, p k n}^{t}-\sum_{p k n \in B_{t}} R_{p k n} W_{p k n}^{t} \geq 0 \\
& \sum_{t \in T} \sum_{i j m \in O_{t}, p k n \in B_{t}} S V_{i j m, p k n, B_{t}+1}^{t}-\sum_{p k n \in B_{t}+1} R_{p k n} W_{p k n}^{t} \leq 0
\end{aligned}
$$

4. Selective placement constraints, the purpose of which is to ensure that reactive waste rock is encapsulated by benign waste rock: 


$$
\begin{aligned}
& \sum_{t \in T} \sum_{p k n \in B_{t}} S\left(P_{R} V_{B, B^{\prime}}^{t}+P_{B} V_{R, B^{\prime}}^{t}\right) \leq P_{B}, \cdots B, R \in O_{t}, \cdots B^{\prime} R^{\prime} \in B_{t} \\
& \sum_{t \in T} \sum_{p k n \in B_{t}} S\left(P_{R} V_{B, R^{\prime}}^{t}+P_{B} V_{R, R^{\prime}}^{t}\right) \geq P_{R}
\end{aligned}
$$

5. Operational constraint, the purpose of which is to ensure that each block from the open pit can only be dumped once in the rock dump:

$$
\sum_{p k n \in B_{t}} W_{p k n}^{t}=1
$$

\subsection{Application of model}

To demonstrate the application of the rock dump scheduling model, the simple, three-dimensional, open pit and rock dump block models depicted in Figure 3 were used. The layout of an open pit is dictated by the shape of the ore body, and the need to maintain pit stability and to construct and maintain haulage ramps out of the pit. Many ore bodies are steeply-dipping, resulting in a deep open pit of relatively small plan dimensions. The shapes and volumes of the open pit blocks are likely to be constant, with the block size defined by the selected "minimum mineable block size", which is a function of the shape of the ore body, the characteristics of the rock, and the blasting and mining methods used. A typical mining block is of the order of $20 \mathrm{~m}$ cubed. The volume of waste rock at each bench of the open pit may vary.
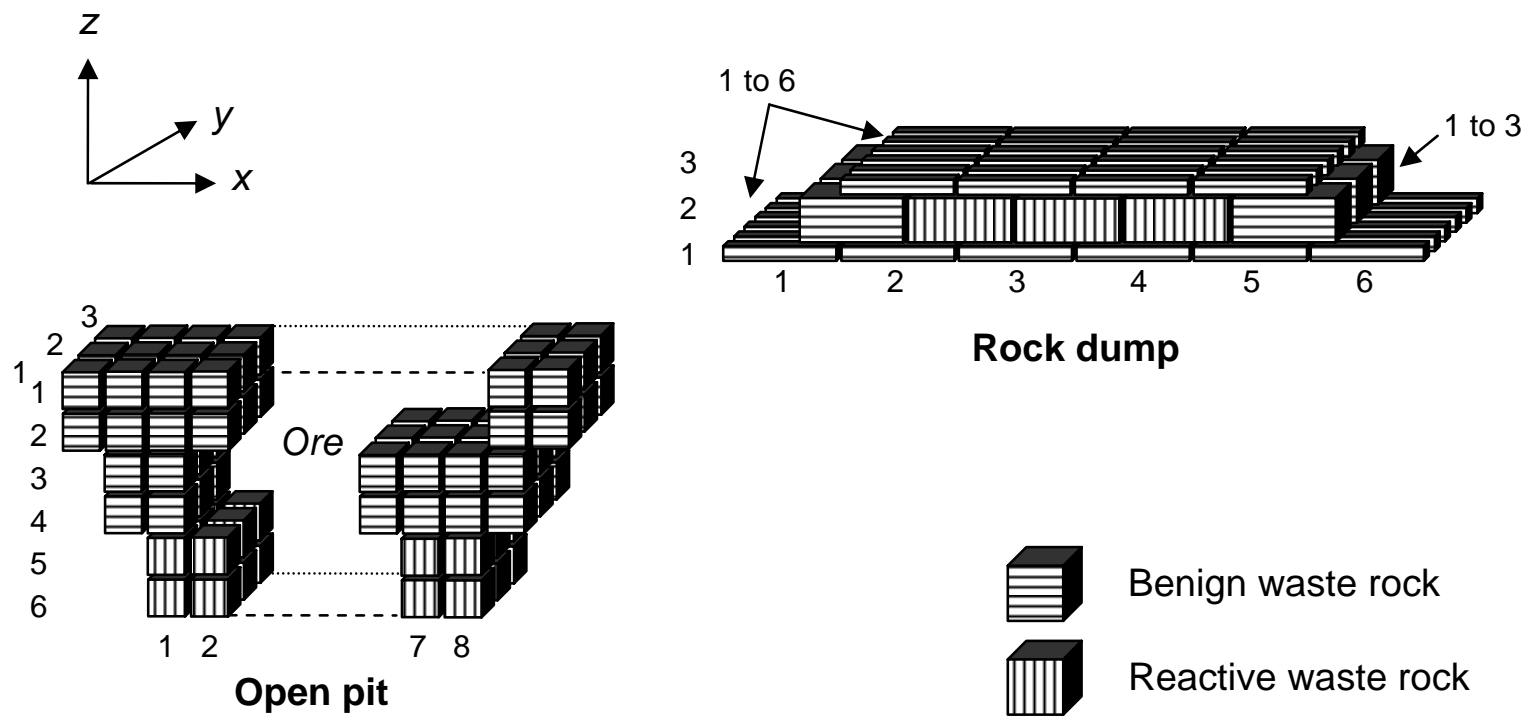

Figure 3 Simple 3-D block models of open pit and rock dump

The high cost of waste rock haulage, low cost of land, and aesthetic considerations, will generally dictate that surface rock dumps cover a large area to relatively low height, in contrast to the shape of open pits. The shapes and volumes of the rock dump blocks may vary, and will likely be different from those of the open pit blocks to allow for swelling on excavation (of typically 130\%) and the geometrical constraints of the rock dump. The storage capacity of the rock dump will vary with the height of each lift and its location. For a constant lift height, due to the set-back of successive lifts to maintain access for haul trucks, the volume contained in each lift will decrease with successive lifts. In Figure 3, thinner base and top lifts were adopted to represent the base layer of benign waste rock and a top store/release cover of benign material, with all reactive waste rock encapsulated by benign waste rock within the centre of the middle lift. 


\section{Results of analysis}

In this demonstration analysis, the notional unit haulage cost was minimised while forcing the reactive waste rock to be encapsulated by benign waste rock blocks in the rock dump of defined geometry. A range of rock dump geometries could be analysed to determine the optimum geometry for the particular mine conditions. In this analysis, the time periods were selected to correspond with the completion of each lift of the rock dump, but much shorter time periods can be used for more refined analyses. The number of open pit blocks that can be scheduled in real applications can be well over 100,000 blocks, and the number of the rock dump blocks can be well over 10,000.

The open pit benign waste rock blocks can be hauled to any of the available benign block locations within the rock dump, during a given time period. For example, the first open pit block to be mined $(1,1,1)$ can be hauled to any of the rock dump locations $(1,1,1)$ to $(6,6,1)$ in the first lift of the rock dump. Subsequent benign waste rock blocks can be hauled to benign waste rock blocks that remain available in the first lift of the rock dump, before filling benign waste rock blocks in subsequent lifts.

The open pit reactive waste rock blocks can only be hauled to the centre of the middle lift of the rock dump, to locations $(2,1,2)$ to $(4,3,2)$, inclusive. This imposes a considerable constraint on the optimisation, and may make a selected rock dump geometry impossible to match to the sequence of mining from the open pit, requiring the analysis of a range of rock dump geometries. Initially, this would be done by trial and error, but experience would later guide the optimisation of the rock dump geometry.

The results of the analysis are summarised in terms of the integer variable $W$, which indicates where each open pit block is to be placed in the rock dump, the volumes $V$ of waste rock hauled from the open pit to each lift of the rock dump or during each time period, and the minimum haulage cost for the selected rock dump geometry.

For a given cost per cubic metre of waste rock hauled and known distances between the open pit and rock dump footprints, the model can generate the minimum haulage cost. This can be expressed in terms of a unit cost per cubic metre of waste rock hauled per kilometre hauled, or the total cost for a given time period, or the total cost for the life of the operation.

\section{Conclusions and future work}

The use of linear programming-based optimisation techniques to generate a model for optimising the construction of surface rock dumps offers the potential to integrate waste rock dumping with open pit mining, minimise waste rock haulage costs, and minimise the potential environmental impacts from rock dump ARD by the selective placement of benign and reactive waste rock and the encapsulation of the reactive waste rock.

The current formulation is a very simple 3-D model, which will later be implemented using real mine data to fully demonstrate its application. It includes block models of the open pit and rock dump, identification of whether the waste rock blocks are benign or reactive, the proposed time scheduling of waste rock haulage from the open pit, and unit haulage costs. Other parameters to later be added to the model will include the cost of the land covered by the rock dump; the haul road routes between the pit and the dump in xyz-space enabling estimation of haulage distances, grades and actual haulage costs; alternative mining methods; in-pit dumping; topsoil and clay stripping and stockpiling for later rehabilitation purposes; the selective placement of benign and reactive rock to encapsulate the reactive rock; rock dump landform shaping; cover placement; and slope treatment. The model will ultimately provide a tool for rock dump scheduling that meets both the operator's economic and environmental goals.

\section{Acknowledgements}

The work reported in this paper has been funded by HLA ENSR as part of a Masters research programme, which is gratefully acknowledged. 


\section{References}

Alford, C. (1995) Optimisation in underground mine design. Proceedings of XXV APCOM Symposium, Brisbane, Australia, 9-14 July 1995, pp. 213-218.

AusIMM (1993) Cost estimation handbook for the Australian mining industry, pp. 279-280.

Dagdelen, K. (1985) Optimum multi period open pit mine production scheduling. PhD Thesis, Colorado School of Mines, USA.

Hartman, H.L. and Mutmansky, J.M. (2002) Introductory Mining Engineering, Second Edition, pp. 2-3. John Wiley and Sons.

Johnson, T.B. (1968) Optimum pit mine production scheduling, Technical Report, University of California, Berkeley.

Kleinmann, R.L.P. (1991) Acid mine drainage: An overview. Proceedings of ASCE Specialty Conference on Energy in the 90's, Pittsburgh, USA, 10-13 March 1991, pp. 281-286.

Nehring, M. and Topal, E. (2007) Production schedule optimisation in underground hard rock mining using mixed integer programming, Proceedings of Project Evaluation Conference, Melbourne, Australia, 19-20 June 2007, pp. $169-175$.

Ramazan, S. (2007) The new fundamental tree algorithm for production scheduling of open pit mines. European Journal of Operational Research, 177(2), pp. 1153-1166.

Topal, E. (2003). Advanced underground mine scheduling using mixed integer programming. PhD Thesis, Colorado School of Mines, USA.

Trout, L.P. (1995) Underground mine production scheduling using mixed integer programming. Proceedings of XXV APCOM Symposium, Brisbane, Australia, 9-14 July 1995, 1995, pp. 395-400.

Wilke, F.L. and Reimer, T. (1977) Optimising the short term production schedule for an open pit iron ore mining operation. Electronics Letters, pp. 425-433.

Williams, D.J., Stolberg, D.J. and Currey, N.A. (2006) Long-term performance of Kidston's “store/release" cover system over potentially acid forming waste rock dumps. Proceedings of Seventh International Conference on Acid Rock Drainage, St Louis, Missouri, USA, 26-30 March 2006, pp. 2385-2396. 